hard pieces of earth. Cut a board which will just lay inside the frame on the seed bed soil. Step on the board and press it down firmly and walk across the bed, turn the board over and walk back and continue this process until the whole bed has been covered or "planked." Sow the seed using one tablespoonful of separated seed to every section of bed twenty feet long by eight feet wide. If it has not been separated use two tablespoonfuls of seed for every twenty-five foot section and rake very lightly with a garden rake. Care should be taken not to draw any earth with the rake. Lay on the board as before and go through the same process until the whole bed is pressed down. Now give it a thorough watering no matter how cold it is or if it should rain at the time, water and cover at once. In sowing the seed some mix it with corn meal, some with land plaster, but I prefer road dust. Corn meal is apt to mold or rot the plants. Land plaster will do if dry seed is planted, but will kill sprouted seed.

In 1903 I began growing experimental tobacco for the U. S. Department of Agriculture under the direction of Prof. A. D. Shamel. We made several crosses from which was selected what is known as the Cooley hybrid. The parent plants were Connecticut Havana seed. as the female and Connecticut grown Sumatra as the male. In this cross a great many types of tobacco developed from the shoe string to the broad leaf type, but by careful selection we have a new tobacco which has great promise. As to the shape of leaf and uniformity of plant it is well settled but should be grown a year or two more and selections made for quality before putting it on the market. It is reported by some who have grown it the past season that the yield was over three thousand pounds per acre. In growth it is a strong vigorous grower with very wide and round shaped leaf. The color is a light to medium cinnamon brown and has a perfect burn.

\title{
VALUE OF THE USE OF IMPROVED VARIETIES OF SUMATRA TOBACCO IN FLORIDA.
}

By H. F. Bostick, Quincy, Fla.

In 1899 the extensive growing of tobacco under shade was begun near Quincy, in Gadsden County, Florida. The previous year a small experimental patch had been planted under slats and the thinness of the leaves and their texture led growers to believe that a tobacco suitable for cigar wrapper purposes could be grown on old cultivated lands, by building shadeś over them. Their previous experience had been that such 
tobacco, if grown in the open, could only be produced with any degree of certainty on virgin soil, freshly cleared of its timber.

A part of the shades erected in 1899 were covered with slats and the others with cheese cloth, the latter being for the most part irrigated. The success of this crop led to great increases of the shaded acreage until today there are several thousand acres of tobacco planted under. shades in Florida and a small portion of southwestern Georgia.

The first year some of the shades were planted in Sumatra and some from Cuban seed (in proportion as the growers had a preference for either type). For several years some of the growers continued to plant the Cuban variety, but as it was found generally that the tobacco grown from Sumatra seed was superior in texture and thinness of leaf and in yield of wrappers, less tobacco was grown of the Cuban variety. Today there is little or none of the Cuban tobacco planted under shade in the entire tobacco growing district.

There is a variety known as the "Big Cuban" that has found favor with some of the growers but in the opinion of the writer this is a hybrid showing characteristics of both the Cuban and Sumatra varieties.

Without question the popular tobacco today for growing under shade is the Sumatra variety, and the effort of all intelligent growers is to secure by careful seed selection a tobacco that will, in burn, texture, and yield of wrappers, in some way approach the ideal Sumatra type. In this they have had valuable assistance from the experts of the Bureau of Plant Industry of the Department of Agriculture. The work of these gentlemen cannot be too highly commended and along the lines laid out by them must come the perfect type of tobacco.

The tendency of the imported Sumatra seed, after two or three years planting in Florida, is to break up and show a wide dissimilarity in shape and size of both leaf and stalk. In such tobacco there is no uniformity in size and shape of leaf which is one of the prime requisites of a successful cigar wrapper tobacco.

While a fairly uniform tobacco can be raised by the ordinary methods, carefully pursued, that is, by the careful selection of the best plants for seed and the close topping and pruning.of all inferior plants, this method by no means goes far enough, as is shown by the fact that with selections made in this way the growers have not been able to grow a tobacco that remained fairly uniform and true to type, for more than one or two crops, but must continually change his seed.

The only successful method, it seems, after carefully selecting the stalks for seed, is to bag the seed heads and in that way prevent cross- 
fertilization. The plants grown from seed saved in this manner have unquestionably shown far less tendency toward breaking up, and remain true to type.

The hope of the grower is that, by careful and diligent selection and improvement of seed, he will finally secure a type of tobacco that will in every way meet the demands of the buyer and so reach the Mecca of his ambition.

\section{HISTORY OF ZIMMER SPANISH TOBACCO.}

-By A. D. Selby, Botantist, Ohio Agricultural Experiment Station, Wooster, O. .

Most persons familiar with tobacco production and with the tobacco trade have heard of the Zimmer Spanish variety which is grown extensively for cigar filler purposes in the Miami Valley region of southwestern Ohio. While it is by no means the only variety largely grown in Ohio and not the only variety grown in the Miami Valley district, it is the dominant sort produced in the state, as well as the chief sort grown in the region just mentioned.

\section{OHIO TOBACCO DISTRICTS.}

Ohio has four distinct tobacco districts whose relative locations and production are shown in the following list, to wit:

1. Cigar filler district, southwestern Ohio, including all, or parts of some thirteen counties. The crop in 1906 in this district was 55,707,553 pounds or 79 per cent of the whole.

2. The Burley district, southwestern, about five counties along the Ohio River, produced 10,121,393 pounds or about 14.2 per cent of the whole.

3. The export district of southeastern Ohio, including many counties, produced $4,359,549$ pounds.

4. The cigar wrapper district of Medina and Wayne counties produced 597,474 pounds, less than 1 per cent of the entire crop grown in that cigar wrapper district.

A very large proportion of the total crop is of the Zimmer Spanish variety, although Seedleaf is grown to a minor extent and latterly Little Dutch in greatly reduced amounts. 